\title{
The effect of opening on building envelope toward daylight performance in Betang House at Central Borneo
}

\author{
Eka Susanti $^{a^{*}}$, Desak Putu Damayantia ${ }^{a}$ Sri Nastiti N. Ekasiwi ${ }^{b}$, Ima Defiana ${ }^{b}$ \\ ${ }^{a}$ Denpasar Experimental Station for Traditional Housing Technology Development, Research Institute For Human Settlement, \\ Ministry of Public Work, Sanur - 80228, Indonesia \\ ${ }^{b}$ Department of Architecture, Sepuluh Nopember Institute of Technology, Surabaya - 60111, Indonesia \\ *Corresponding author. Tel.: +62-838-318-67099. \\ E-mail address: eka.e.susan@gmail.com
}

\begin{abstract}
The traditional house is able to adapt the climate around them and it can reduce the burden of energy use to adjust the comfort of occupants. The development pattern of occupants' activity adjusts to a modern life that indirectly affects the function and condition of the building. This gives rise to a new phenomenon, whether development sheath openings in buildings can still meet the needs of lighting for the activity of the occupants. This research was conducted with the aim to clarify and identify the deployment sheath openings in buildings on the performance of natural lighting in Betang House. The method experiment with the help simulation is used to find a causal relationship from deployment sheath openings in Betang House building performance against natural lighting. The experiment is conducted with the simulation using Autodesk Ecotect Analysis 2011. The final result of the research indicates deployment openings in the façade have natural lighting performance that already meet the standards of the lighting for the activity. Deployment openings with the addition of extents openings could increase illuminantion and daylight factor space by $10 \%$ and $14 \%$, but the value of the resulting illuminantion uniformity is not too high. The addition of height can increase the value of daylight factor of $13 \%$. The ratio of lighting uniformity additional height opening is higher, but that resulted being lower illuminantion $0.3 \%$. Rumbak tahansengan deployment at facade can improve the ratio of the lighting uniformity for activity up to $9.6 \%$.
\end{abstract}

Keywords: opening, daylighting performance, traditional house, passive system.

\section{Introduction}

Traditional House in the tropic climate in generally using a passive system on the façade to fulfill natural ventilation or daylight needs. On the building of Betang Traditional house applying natural opening on façade as the main lighting source. The Opening on façade has some type of configuration of the side openings such as windows, doors, roster and rumbak tahansengan. With the use of openings for entry of daylight, that's helped to reduce the energy burden to use artificial light from morning until afternoon. The existence of the side window, door, roster and rumbak tahansengan at Betang House has two main functions, i.e. as a source of daylight, and also at the same time as cross ventilation to circulate fresh air into the room (2).

When Reviewed with the above-mentioned patterns of activity among inmates in traditional building towards the development of modern era, arising of phenomena in which the function of the traditional house that initially followed the pattern of activity of society in the past, have to adjust the pattern of activity of today's society. The needs of the community's past activity in the morning to afternoon many done in outdoors, so the lack of openings such as typology deployment in space, glare or less uniformity of daylight distribution to the rest of the room cannot be felt directly 
affect the activity of the occupants. Patterns of community activity changing have been following the development of the modern era. Occupants in this time also have activity inside house start from morning until afternoon. And then an opening in building facade deployment requires a review in order to fulfill of lighting needs for activity.

With consideration of energy savings and sustainability of nusantara architecture, the openings in Betang House façade sheath is part of traditional architecture are preserved until nowadays as lighting passive system. Of these openings are expected to fulfill daylight needs to support occupants activity in the building. Therefore required a review of the architectural creation of traditional buildings in the Indonesian archipelago, is the use of openings can still function in line and fulfill the convenience of activity at this time.

This research was conducted with the aim to clarify and identify the performance of daylight, as well as the influence of deployment sheath opening in Betang House Building. The fulfillment of the daylight needs is examined from the quality of daylight are obtained. This study applies the standard guide of daylight as a performance assessment of illumination and daylight factor value to relate with the daylight needs for occupants activities in the room.

\section{Research Theory}

Strategy for Natural lighting design affects the achievement of lighting level fulfillment in the room. The penetration and spread of daylight trough the openings in the façade building can be influenced by several aspects include the shape of the room, spacious space, depth, and height of openings. The form of a building not only determines the possibility of vertical and horizontal opening but also how much of the area can be accessed by daylight from the side lighting. The sleek room will maximize space in that exposure to sunlight. The depth of space has an effect directly against the intensity of the illumination of natural light in the building. More immersive space of the room then the distribution of daylight will be accepted on the wane and uneven. More getting away from the openings, then daylight it brings will be increasingly reduced.

The quantity of the openings as the source of daylight can be adapted to the area and height of openings in facades in order to accommodate the needs of lighting inside the buildings. The Higher size of the window and placement of the openings will be more daylight that can distribute into the room. The height of openings that approaching the ceiling has a lot potential of good distribution of daylight and will be reflected more optimum through the ceiling into the room.

The width opening in building façade larger, so more lighting will be distributed into the room. The phenomenon of daylight distribution through the openings in building façade describe that the height of the aperture determines the depth of daylight penetration, while the width of the aperture determines the spread of daylight into the room. The size, shape, and position of the openings affect the scope of daylight distribution into the room.

Variables associated with the performance of daylight through the openings in the sheath of the building include the types of openings, with the parameters area and the height of the openings from the surface area of work. The total area of the openings in façade and height of openings against the floor surface effect on light distribution in space, the quality of daylight and depth of range area can get a distribution of daylight. The determination of variable is based on daylight strategy basic of the theory, namely the distribution of daylight into the building, one of which is determined by openings design. As well as the depth and height of the building if the extents associated with the building would affect how much illumination quantity of daylight that enters the room.

Daylight performance on buildings can be indicated by checking illumination and daylight factor needs in space with particular activities needs. One of the measures used to describe the quality of lighting performance distribution has been the uniformity ratio. This measurement is usually expressed as the ratio of average illumination to minimum illumination. A typical number of good quality lighting has been a uniformity ratio checked of 0.4 as a minimum parameter correction.

According to lighting theory from (Lechner, 2009) typical daylight factor in each space and the minimum value of daylight factor on each type of room vary, the following standard daylight factor used at home from several sources: 
Table 1. Typical Minimum Daylight Factor

\begin{tabular}{lc}
\hline \multicolumn{1}{c}{ Type of Space } & Daylight Factor (\%) \\
\hline Art Studios, Galleries & $4-6$ \\
Factories, laboratories & $3-5$ \\
Offices, classrooms, gymnasiums, kitchens & 2 \\
Lobbies, lounges, living rooms, churches & 1 \\
Corridors, bedrooms & 0.5 \\
\hline
\end{tabular}

Source: Lechner, 2009: 391

Table 2. Daylight Factor Standard for Residence

\begin{tabular}{lc}
\hline \multicolumn{1}{c}{ Type of Room } & Minimum Daylight Factor ( \% ) \\
\hline Kitchen, generally & $1 \%$ \\
Kitchen, on the work table & $1.5 \%$ \\
Living room, generally & $0.5 \%$ \\
Living room, a desk for writing & $1.5 \%$ \\
Bedroom, generally & $0.25 \%$ \\
Bedroom, dressing table & $1 \%$ \\
Circulation & $0.2 \%$ \\
\hline
\end{tabular}
Source: Baker, 2001

Table 3. Daylight Factor Standard for Residence

\begin{tabular}{lcc}
\hline \multicolumn{1}{c}{ Type of Room } & Minimum DF & Minimum spacious of space \\
\hline Living room & $1 \%$ & $8 \mathrm{~m}^{2}$, half of depth space \\
Bedroom & $0.5 \%$ & $6 \mathrm{~m}^{2}$, half of depth space \\
Kitchen and Pantry & $2 \%$ & $5 \mathrm{~m}^{2}$, half of depth space \\
\hline Source: Evans, 1981
\end{tabular}

\section{Method}

The method used is an experiment with the help of simulation. The experimental method used with the purpose to find a causal relationship from deployment sheath openings in building on the performance of natural lighting in Betang House. Direct observations and measurements can be performed on the object of research, but with consideration of limitations time and the limitations of research to review more in physical condition of the building towards something to do with the performance of lighting, and then used the simulation as a tool in research

Modeling of an experiment using software called Ecotect Analysis 2011, with the model of buildings follows the original building condition of Betang House. Betang house building form is staging house with a height of floor from a ground level around $1.9 \mathrm{~m}$. Betang house façade using planks arranged meetings so as not to allow gap existence on the floor, wall, and ceiling. Betang house building relies on sunlight as a source of lighting in the morning until late afternoon. The lighting system uses openings in the sheath of the buildings as a source of daylight into the room. An opening in building façade is generally in the form of window, door, roster and rumbak tahansengan as in Figure 3. The dimension of the openings adapted to traditional mores in Betang House building.

The inside of Betang House is divided into several rooms that have a function and frequency of occupant activity. This research is focused on the living room, bedroom, los (living room 2), family room and kitchen as shown in Figure 1. Selection of the room will be measured based on consideration there are openings as the main source of natural 
lighting and a pattern of activities that many occupants carried out in this area. Measuring point in each room has a distance $1 \mathrm{~m}$ or $0.5 \mathrm{~m}$ from the edge of the wall in accordance with the total area of the room shown in Figure 2. Measuring point placed on the areas of work is measured from the height of $0.7 \mathrm{~m}$ from the floor surface in each room.

The election of time experiment based on analysis theory of daylight should be reviewing daylight data at least three days in a year, each at least three times from each day (09:00 am, 12pm and $3 \mathrm{pm}$ match local time). But with using simulation can shorten experiment time with taking time out during the day $(12.00 \mathrm{pm})$. Measurement of experiment conditioned on the third week of July with overcast sky conditions. Four modeling with the different conditioning of openings in building façade that is to represent each of the experiment as shown in Figure 4. Classification and details on each experiment, among others:

- Conditioning 1 - According to existing condition (E1)

On First conditioning is based on the physical condition of Betang House. Openings in each room follow the original condition of the existing, height position and number of openings is created the same way as on the condition of the field. On the first conditioning; side window, door and roster in state conditioned is open from morning until late afternoon.

- $\quad$ Conditioning 2 - Addition wide of openings (E2)

On Second conditioning performed with addition wide of opening, this conditioning adding wide of the opening toward each side of façade that contained an aperture. Second conditioning is addition a side window and roster on each side of the room without changing the height of openings. Setting and replacement of additional openings customize the wide of each side of the room. On second conditioning, there is no special treatment for the door. The Opening patterns from side window, door, and roster in conditioned in a state on open from morning until late afternoon

- Conditioning 3 - Addition height of openings (E3)

On Third conditioning is performed by adding the height of side window without changing the number of openings. Opening in room follows the original existing condition and number of openings each room is made same as on the existing. The height of openings in Betang House generally 0.7-0.9 $\mathrm{m}$, it was therefore changed to $1 \mathrm{~m}$ from the floor surface by adding the height of the window. On third conditioning, there is no special treatment for the door. The Opening patterns from side window, door, and roster in conditioned in a state on open from morning until late afternoon

- Condition 4 - Addition rumbak tahansengan on building façade

On fourth Conditioning is the addition of rumbak tahansengan with the aim to find out the effect of using rumbak tahansengan on lighting performance as typical Betang House opening. In fourth conditioning not using ceiling in the room. On the right side wall of the living room and left side wall in the living room 2 performed adding of height as the gavel wall. Change roof shape to fit the shape of the roof at original Betang House that used rumbak tahansengan. This conditioning on the left and right side walls of buildings created high approaching the roof as a place of laying rumbak tahansengan. The opening pattern of the side window, door, roster in a state conditioned is open from morning until late afternoon. Rumbak tahansengan left open all day without any cover that blocks. 

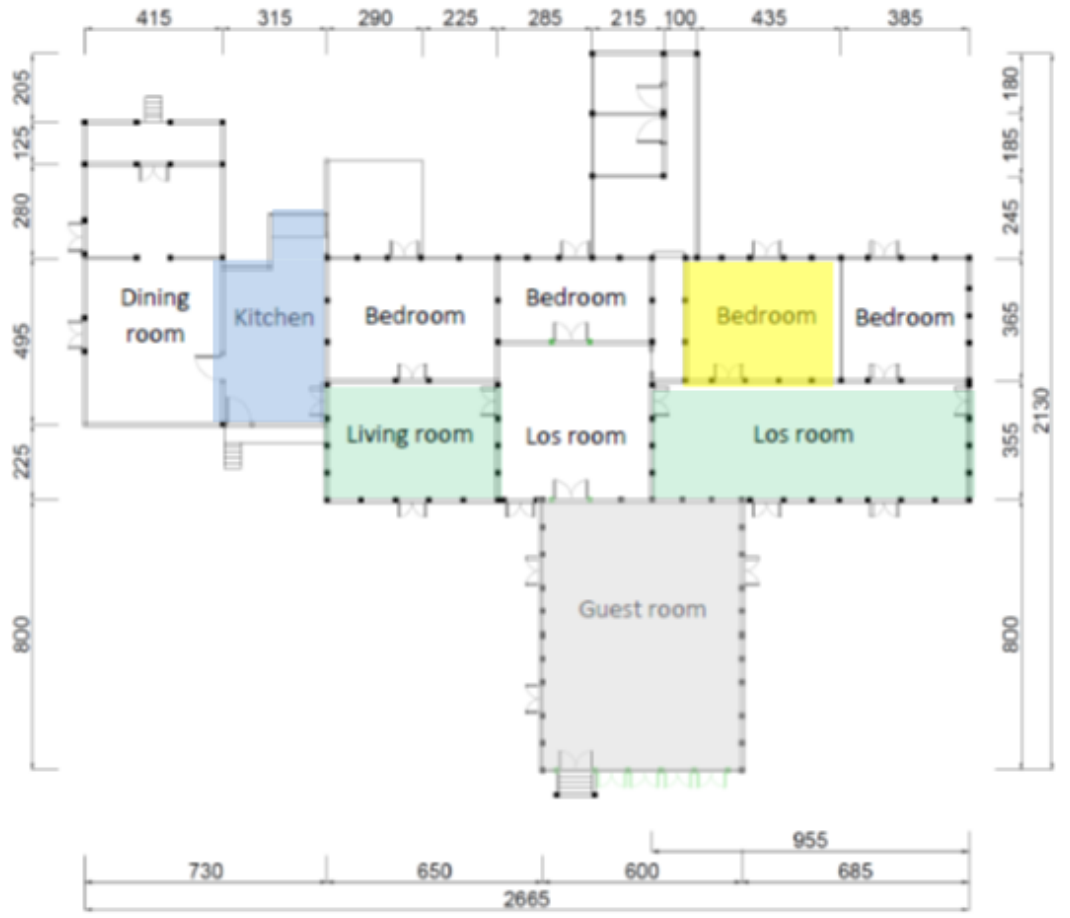

Fig. 1. Floor plan of the room as the place of field measurement.

Living Room

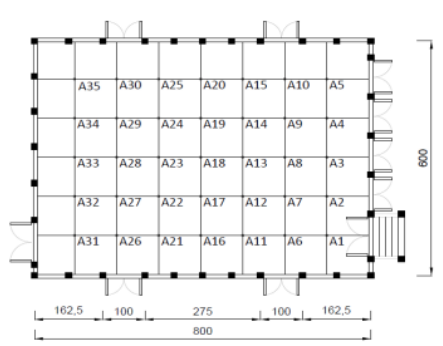

Family Room

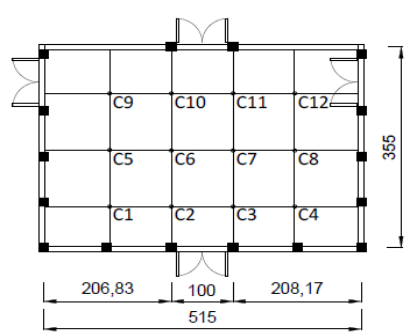

Los Room (Living Room 2)

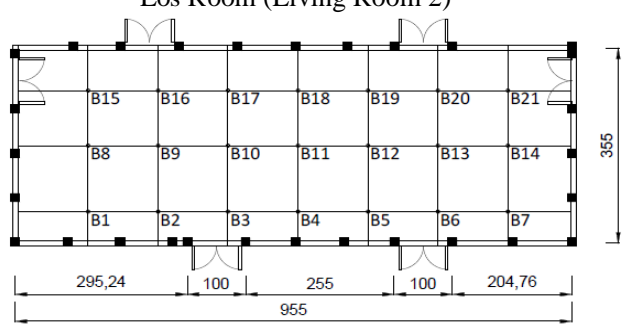

Bed Room

Kitchen
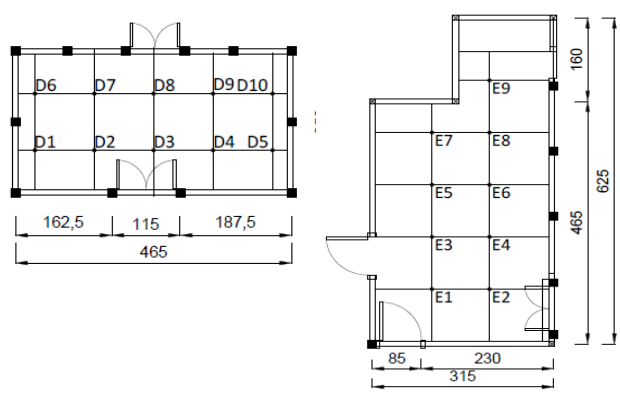

Fig. 2. Measurement points in each room at Betang House. 


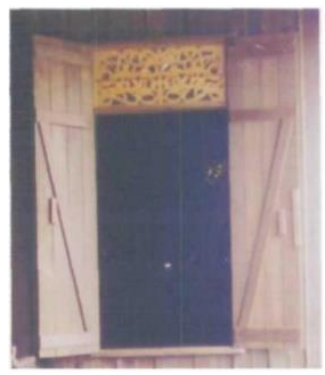

(a) Window

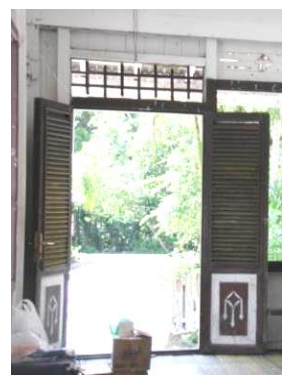

(b) Door

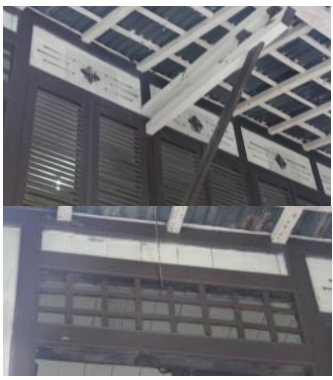

(c) Roster

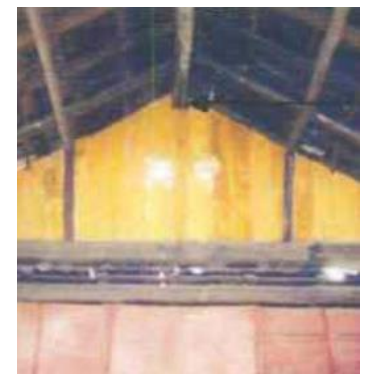

(d) Rumbak Tahansengan

Fig. 3. (a), (b), (c), (d) Type of openings at Betang House.
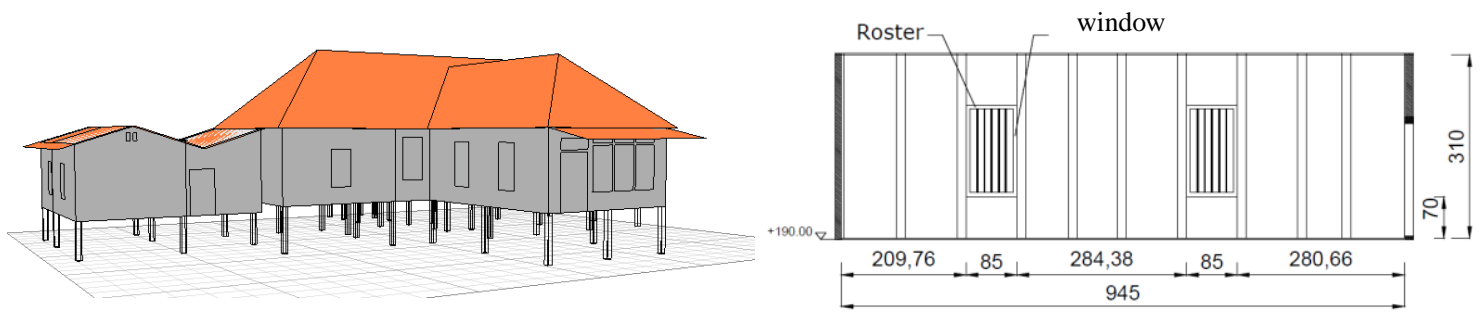

(a) Conditioning 1 - According to existing condition (E1)
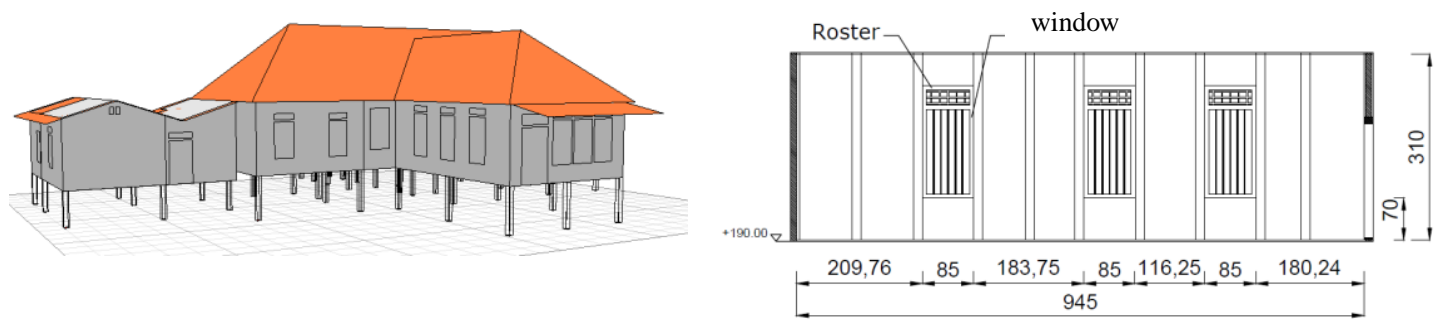

(b) Conditioning 2 - Additıon wide of openıng (É2)
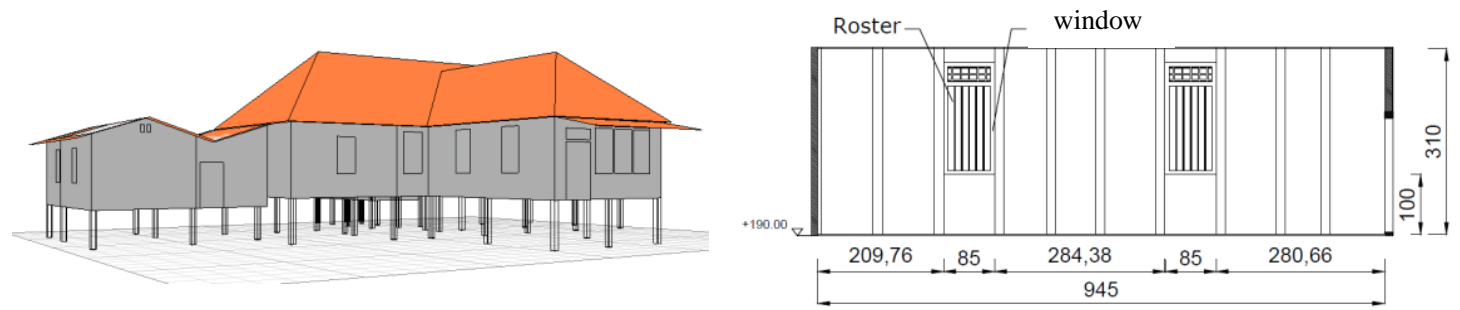

(c) Conditioning 3 - Addition height of opening (E3)
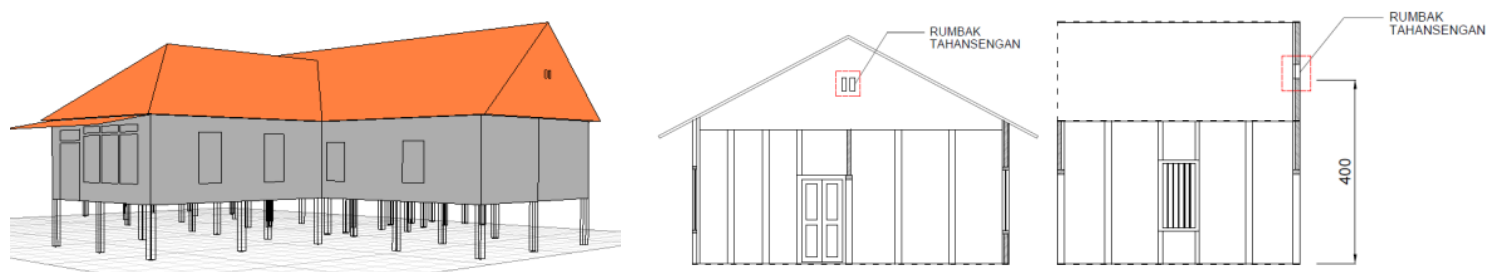

(d) Conditioning 4 - Addition rumbak tahansengan (E4)

Fig. 4. (a), (b), (c), (d) Modeling each experiment conditioning with simulation. 
Based on related activities; kitchen, living room, and the bedroom have activities with the needs of the visual task in high contrast so that the standard of illumination is high compared to the other examined. Table 4 is a standard illumination and daylight factor which is used as a reference for the assessments has been adjusted to the intensity of activity in space.

Table 4. Illumination and daylight factor standard in room.

\begin{tabular}{ccc}
\hline Room & Illumination Standard & Minimum Standard of Daylight Factor (100\%) \\
\hline Living Room & $50-150$ lux & $0.25-1 \%$ \\
Los Room (Living Room 2) & $50-150$ lux & $0.25-1 \%$ \\
Family Room & $120-500$ lux & $2-3 \%$ \\
Bed Room & $120-500$ lux & $0.5-2 \%$ \\
Kitchen & $20-500$ lux & $2-3 \%$ \\
\hline
\end{tabular}

\section{Result and Discussion}

The analysis divided into four main categories, i.e., daylight performance, daylight factor performance in each room, uniformity ratio that indicates the quality of daylight distribution in space inside the building, distribution of natural light from the openings in the facade of the building.

\subsection{Daylight Performance}

In Table 5, the quality of lighting in each conditioning compared to lighting standard, an overall average of illumination value that resulting is above illumination requirements. The resulting of illumination value in each conditioning on each room is quite diverse. Illumination value of E3 is lower than E1, the decline is not too significant, i.e. $2 \%$ of E1 illumination average at the room with wide areas like a living room and los room (living room 2). But illumination distribution in each room is obtained that illumination value between another point by point at E3 didn't have too significant a comparison and coverage of illumination are more evenly distributed. This supports the theory that higher position or size of the window, the more space can get daylight [4].

E2 shows an increase in the Illumination quality and maximum Illumination value larger in compare to the other conditioning with an illumination average 570 lux up to 1714 lux. When compared with E1, additions wide of the opening can increase illumination quantity of 91 lux than initial conditions of 823 lux. It fits with the theory that illumination space will grow along with the increasing area of openings [4].

E1 and E4 opening in each room is conditioned in accordance with existing, but from the result of the simulation showed the illumination average difference between that conditioning. Illumination averages generated on E4 lower than E1. On E4 decline an average of up to $32 \%$ on living room 2, family room and bedroom

Table 5. Comparison of the average value of illumination standard with lighting standard in each room.

\begin{tabular}{cccccc}
\hline \multirow{2}{*}{ Room } & Illumination Standard & \multicolumn{4}{c}{ Illumination Average } \\
\cline { 3 - 6 } & & E1 & E2 & E3 & E4 \\
\hline Living Room & $50-150$ lux & 823 & 804 & 914 & 824 \\
Living Room 2 & $50-150$ lux & 643 & 631 & 674 & 441 \\
Family Room & $120-500$ lux & 554 & 554 & 584 & 431 \\
Bed Room & $120-500$ lux & 478 & 478 & 570 & 312 \\
Kitchen & $120-500$ lux & 1723 & 1723 & 1714 & 1664 \\
\hline
\end{tabular}




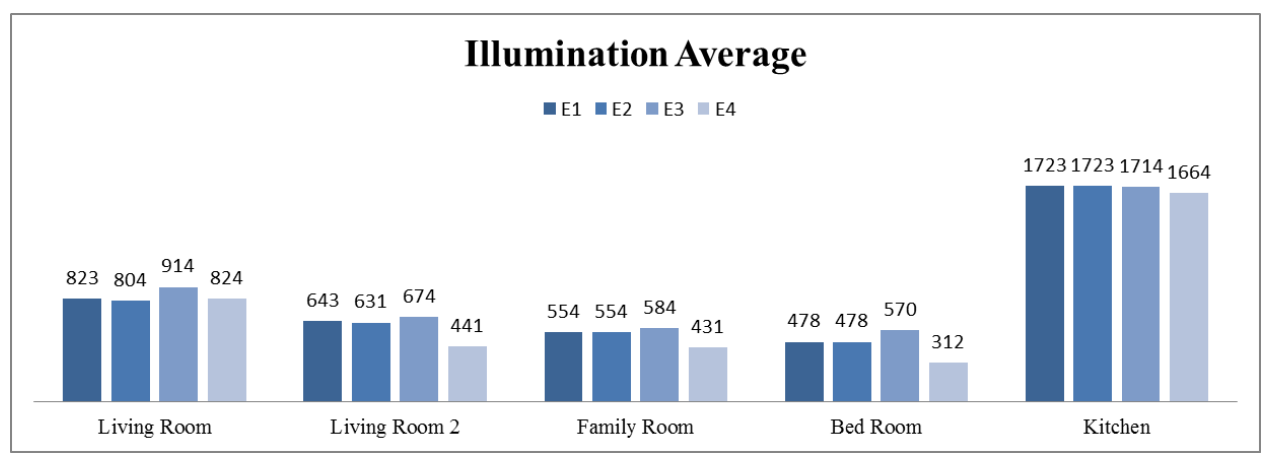

Fig. 5. the average value of illumination standard with lighting standard in each room.

\subsection{Daylight Factor Performance}

Table 6. Comparison of the average value of daylight factor standard with lighting standard in each room

\begin{tabular}{cccccc}
\hline \multirow{2}{*}{ Room } & Daylight Factor Standard & \multicolumn{4}{c}{ Daylight Factor Average } \\
\cline { 3 - 6 } & & E1 & E2 & E3 & E4 \\
\hline Living Room & $0.25 \%-1 \%$ & 8.24 & 7.93 & 9.31 & 8.24 \\
Living Room 2 & $0.25 \%-1 \%$ & 6.32 & 6.3 & 6.74 & 4.43 \\
Family Room & $2 \%-3 \%$ & 5.54 & 5.72 & 6.16 & 4.31 \\
Bed Room & $0.5 \%-2 \%$ & 4.78 & 4.78 & 5.7 & 3.12 \\
Kitchen & $2 \%-3 \%$ & 17.23 & 17.23 & 14.14 & 15.99 \\
\hline
\end{tabular}

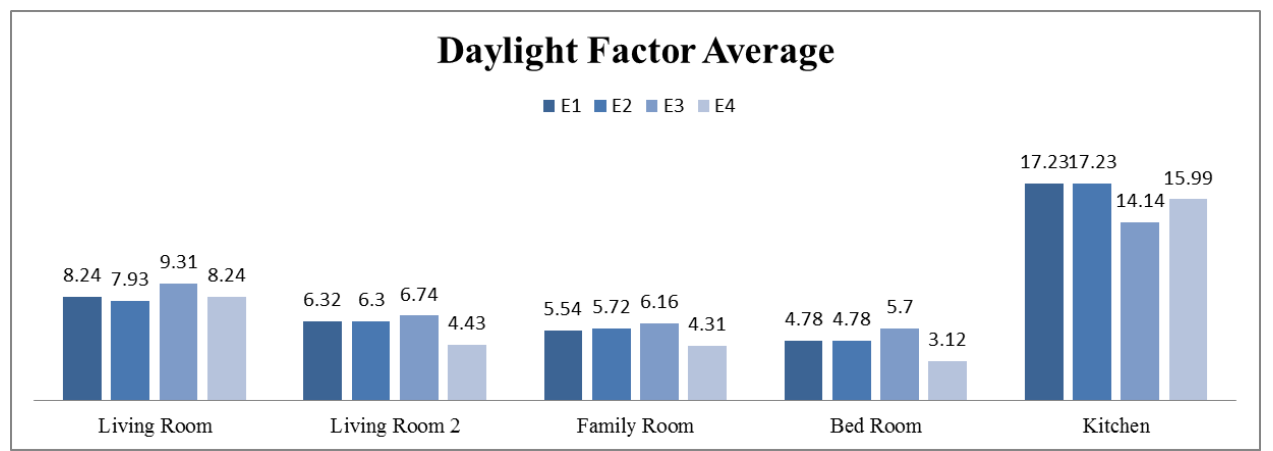

Fig. 6. the average value of daylight factor standard with lighting standard in each room.

In a general comparison of the average value of daylight factor on each room shows every openings conditioning can fulfill daylight factor standard for activity as shown in Table 6. The value of daylight factor which is in compliance with daylight factor standard in the family room has a percentage of $100 \%$ for each conditioning. Overall room at each conditioning has a value of daylight factor average above 3\%. The increase in the daylight factor average overall biggest room is E2, i.e amounting 13\% higher than E1. More extensive the openings on the side of façade allow more daylight that can go into the room so as to raise the value of daylight factor space [4]. At E3 didn't add an average of daylight factor quantity. As for the difference in the decline on increased by conditioning 1 i.e. amounted to $0.3 \%$. Average daylight factor low occurred on E4 amounting to $3.12 \%$ in the bedroom. If compared to E1 and E4, the results of the simulation showed the illumination average difference between the two aforementioned conditioning. Daylight factor average resulting from E4 is lower than E1. The average differences between each room at E4 lower $23 \%$ from E1. These conditions are influenced by the changing shape of the roof of the addition 
of rumbak tahansengan that caused shapes the roof on E4 is different from other conditioning. The addition of the walls, the roof has the gavel and not using the ceiling causes the volume of space becomes larger and the reflection of natural light into the space more spread. The value of identified difference between each measurement point, vulnerable daylight factor on E4 is not too much description, the area near the area away from the openings instead.

\subsection{Uniformity Ratio}

The results of the simulation showed that each room has examined good uniformity value on any conditioning of openings. Uniformity value achieved above the minimum value checked i.e. 0.4. Uniformity of approach spaces on some value of 1 so it can be said to be uniform. Based on the results of Table 7 that found the phenomenon on average the addition of height and area of the openings can produce a large quantity of illumination, but the value of uniformity declined. In Figure 8 on E2 and E3, some of the room like a living room, bedroom and kitchen have the same uniformity with E1. There is a difference in value between the E1 E2 with uniformity. The addition of altitude effect on the range of lighting in the space, the more illumination can distribute of reaching into space, the difference in the resulting uniformity is not too significant, i.e. by $8 \%$ compared with the average value of the uniformity of each room E1. In the room with huge openings such as extents in the living room and living room 2 obtained the lowest E3. In the living room with openings on the third side of the facade, the difference in uniformity checked ratio obtained up to $79 \%$ of the value of the uniformity $0.57 \mathrm{in}$ E1. The addition of extents openings give effect illumination spread fuller into space, but there is a difference illumination between a fairly significant between areas near the openings with the area away from the openings. That is because the number of openings on the side facade allows natural light can distribute into the room with a lot of quantity. Average of Illumination quantity in each room of E4 is quite low, but of the whole conditioning Illumination uniformity of E4 is fairly evenly i.e. 0.57-0.91. When compared with E1, Illumination uniformity increased obtained up to $9.6 \%$ of openings in accordance with existing conditions that do not use rumbak tahansengan of 0.83 . That condition quite good considering deployment rumbak tahansengan with changes roof shape so that the volume of space become increasingly large and light reflected can diffuse as it does not come with the ceiling. Deployment rumbak tahansengan can improve the condition of lighting space more evenly go to that cannot get enough of illumination quantity of side window, door or roster.

Table 7. Comparison of uniformity ratio in each room.

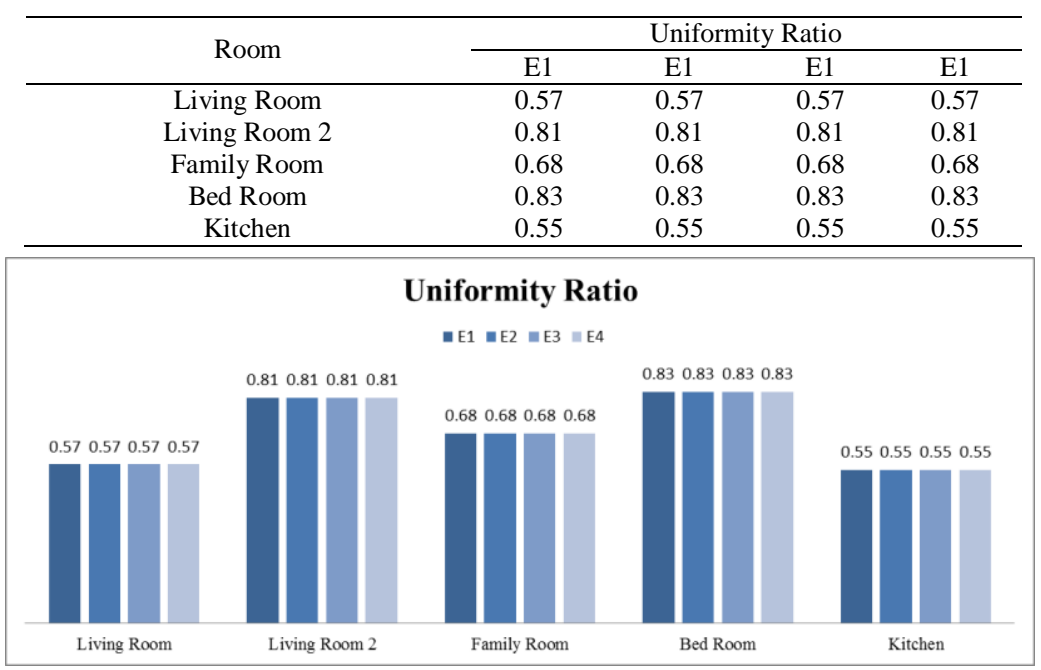

Fig. 7. uniformity ratio in each room. 


\subsection{Daylight Distribution in Room}

Overall of a point on E1, E2, E3 and E4 has a value that is more than a lighting standard needed in activity in accordance with room activities. On Figure 8, it can be observed that E3 shows a wider range of illumination backward of room compared to E1. E2 shows illumination quantity more generated in compare to the other conditioning, a however area with high illumination contour concentrated on the area that close to openings. E4 has lower illumination quantity when compared to other conditioning, but the illumination contours of the resulting on E4 more prevalent than other conditioning. There was no significant difference in color that each point of measurement.

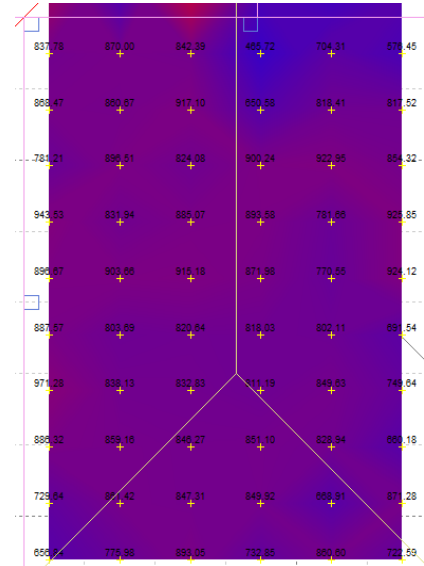

(E1)

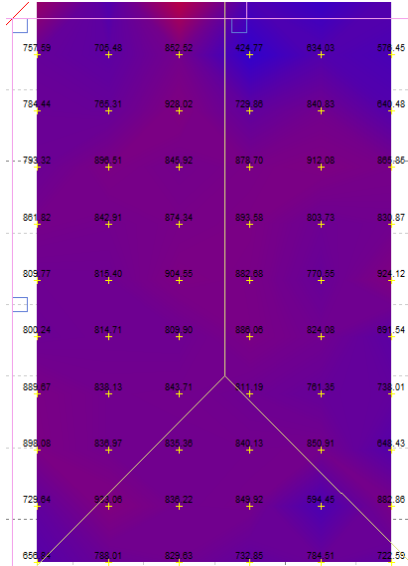

(E2)

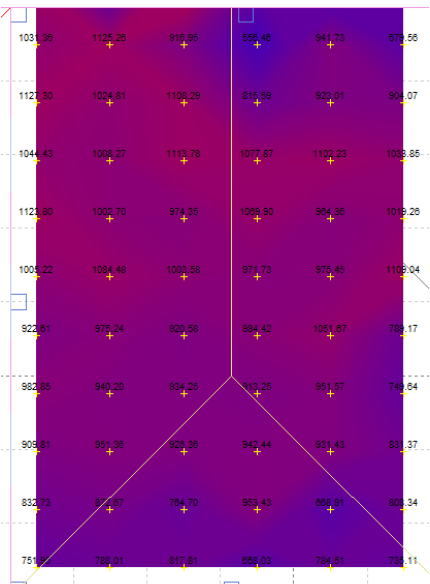

(E3)

a. $\quad$ Living Room

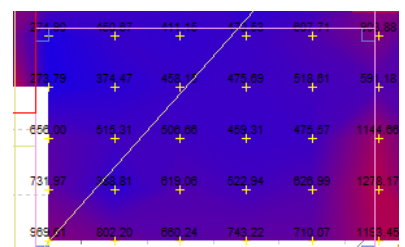

(E1)

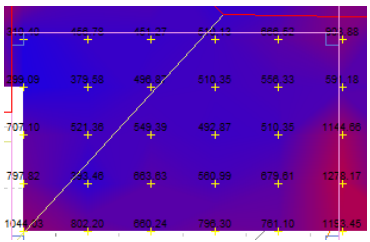

(E2)

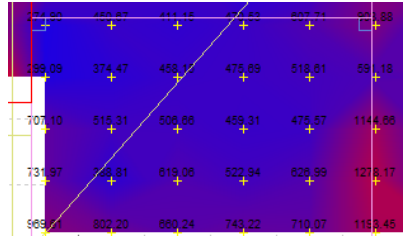

(E3)

b. Family Room

Description:

High Illumination

Low Illumination

Fig. 8. Illumination distribution at (a.) living room, (b.) family room.

\section{Conclusion}

The Above Analysis and discussion have concluded that daylight performance from applying openings in the building façade is quite good. This is indicated by daylight performance in each room can meet the lighting standards for the activities. Daylight performance can be fulfilled starting from morning to afternoon, but in the afternoon the daylight factor began declining in quantity. The average value of daylight factor generated considerable i.e. between $7.93 \%-9.31 \%$ in the living room, $4.43 \% 6.74 \%$ in living room $2,4.31 \%-6.16 \%$ in the family room, $3.12 \%-5.7 \%$ in the bedroom and $15.99 \%-17 \%$ in the kitchen. Applying the openings with the addition of extents openings can improve illumination and daylight factor by $10 \%$ and $14 \%$, but the value of uniformity ratio is not too high. With addition height of the openings can increase the value of daylight factor of $13 \%$, greater lighting uniformity ratios, but the 
illumination resulting is lower $0.3 \%$ of normal conditions. With applying rumbak tahansengan at Betang House can improve the uniformity ratio of lighting for activity up to $9.6 \%$ compared to that before using the rumbak tahansengan.

\section{Acknowledgment}

The authors want to acknowledge Master Architecture field of expertise Environment Architecture, Department of Architecture, Sepuluh Nopember Institute of Technology Surabaya for Support in realizing and complete this paper. Special thanks and high appreciation is also delivered to Denpasar Experimental Station for Traditional Housing Technology Development, Research Institute for Human Settlement, Ministry of Public Work, which has been supporting in research to Palangka Raya, Central Borneo, Indonesia in 2014 which allow the possibility to get the field of measurement data used in this paper.

\section{References}

Lechner, N. (2009). Heating, cooling, lighting : sustainable design methods for architects. John Wiley \& Sons. 